\title{
The Effects Of Macroeconomic And Policy Uncertainty On Exchange Rate Risk Premium
}

Juan Angel Jimenez Martin, (E-mail: Juanangel@ccee.ucm.es), Universidad Compulutensede Madrid, Spain Rodrigo Peruga Urrea, (Deceased 1999), Universidad Compulutensede Madrid, Spain

\begin{abstract}
The goal of this paper is to identify the main determinants of the risk premium in some European currency markets just before the EMU. To that extent, we start from Lucas (1982) exchange rate model and derive an analytical expression for the forward premium. This expression includes money and production variables and it is quite standard, except for the inclusion of macroeconomic policy risk. Under some standard assumptions, this formula simplifies substantially and becomes amenable to regression analysis. Then, using standard measures of money and production, as well as interest rate swaps as indicators of macroeconomic policy risk, the theoretical expression is estimated. We provide evidence suggesting that it is policy uncertainty, much more than fundamental macroeconomic uncertainty, which determined risk premium over the convergence process to the euro. Whether these results can be extended to similar experiences for other currency unions remains open for future research.
\end{abstract}

\section{INTRODUCTION}

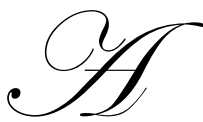

$\mathrm{n}$ intense research effort has been paid in recent years to characterize the determinants of excess returns in the forward market for exchange rates [see Hodrick, 1987 and Bekaert and Hodrick, 1992, among many others]. As a consequence, significant progress has been made in identifying the factors that lead to the presence of a risk premium in exchange rates, although characterizing how its size changes over time remains an open question.

A variety of approaches have been used to analyze excess returns in forward contracts for exchange rates. First, portfolio selection models assume that the risk premium depends on the supply of assets and the risk aversion of investors (Frankel, 1982). A second approach is embedded into intertemporal asset valuation models, developed after Lucas (1982), that establish a link between financial markets and markets for consumption commodities. Along this latter line, Hansen and Hodrick (1983), Kaminsky and Peruga (1990) and $\mathrm{Hu}$ (1997) show that the exchange rate is a function of the fundamental variables in the model, money supply and output or real income. In equilibrium, the excess return in the currency market is determined by the preferences of private agents and the volatility of the fundamental variables in the

economy. Finally, a third approach suggests that the excess return is related to the so-called 'peso problem' ${ }^{11}$ Krasker, 1980, Borensztein, 1987, Lewis, 1988 and Kaminsky and Peruga, 1991). Agents may have solid expectations of a future change in policy which will affect the exchange rate, although the timing of that change is uncertain. Then, the 'peso' effect will materialize, even if the change in policy never arises.

\footnotetext{
1 The 'peso problem' name originated from studies made on the Mexican peso at the beginning of the 70s. Traders in currency markets anticipated a devaluation, and for some time the peso was being sold at a discount in forward markets, even though the government maintained its value until 1976. This effect made the forward exchange rate to deviate from being an unbiased predictor of future spot exchange rate over that period of time.
} 
This paper is a new attempt to identify the determinants of the risk premium in the currency market. Specifically, our work is motivated by the transition period to the European currency and the many episodes of increased uncertainty on the success of that process as well as on the specific currencies which would form the European monetary union. The effect of uncertainty on each currency was different, depending on the macroeconomic conditions of their respective countries, leading to speculative attacks against the weakest currencies in the European Monetary System (EMS). Between 1992 and 1998, macroeconomic uncertainty affected the level of risk on different currencies. Our goal is to present and test a model explaining the determinants of risk premium in currency markets as an explicit function of the amount of uncertainty observed by private agents.

We start by developing a theoretical model to identify two possible sources of macroeconomic uncertainty. This extends previous work by combining the second and third approaches mentioned above. Using the setup in $\mathrm{Hu}$ (1997), we establish the relationship between the excess return in forward contracts and the volatility of money supply and output. That way, we can measure the effect of fundamental macroeconomic uncertainty on the risk premium in the exchange rate. Additionally, we incorporate into the model another relevant source of uncertainty, emerging from anticipations of changes in macroeconomic policy. We want to capture the historical perception that some countries in the EMS would have to introduce some policy changes to control inflation and government deficit in order to eventually gain access to the European currency. Specifically, changes in government expenditure policy could have a nontrivial effect on aggregate demand and relative prices. The perception that there was a nonzero probability that such changes would have to be introduced increased the uncertainty on the currency exchange rate for those countries.

We test this risk premium model, which incorporates the two mentioned sources of uncertainty, considering bilateral exchanges between the French franc, Sterling pound, Spanish peseta, all with the Deutsche mark. Our results show that the bigger explanatory power is attained for the post-1994 period, once the national parliaments approved the convergence criteria to the common European currency. Furthermore, it is uncertainty on macroeconomic policy which exhibits a more systematic explanatory power for the exchange rate risk premium, with uncertainty on the fundamentals of the economy playing a minor role.

Three western European countries in the EMS, UK, Demark and Sweden, have not yet adopted the euro. Besides, the European Union is in the process of expanding to incorporate 11 new Eastern European countries as new members. Hence, although we use the initial convergence process to the euro as an illustration, our methodology can be used to analyze possible exchange rate risk premium in these countries. A similar analysis could also be applied if common currency areas in Latin America or South East Asia are eventually approved.

In the second section we develop the theoretical model, and explain how to produce an analytical expression for the forward exchange risk premium from the Euler condition on aggregate consumption. In the third section we describe a particular model by specifying private agents preferences and the stochastic behavior of the main variables, to derive an analytical expression for the risk premium allowing for statistical tests to be performed. In the fourth section we estimate the equation for the risk premium and characterize the role of uncertainty. In the fifth section we present the main conclusions.

\section{THEORETICAL MODEL}

We consider a dynamic, general equilibrium model similar to that Lucas (1982). From the intertemporal Euler condition for consumption we derive expressions for equilibrium spot and forward exchange rates. Finally, these expressions are used to characterize excess returns in exchange markets and the corresponding risk premium in forward rates.

The model considers two countries (domestic and foreign) and two perishable commodities, $x^{D}$ and $x^{F}$. In each country, a different currency is used to pay for transactions in their respective commodities. Each period $t$, the domestic (foreign) country receives a stochastic endowment $Y_{t}^{D}\left(Y_{t}^{F}\right)$ of good $x^{D}\left(x^{F}\right)$, and zero units of the other commodity. Each country also receives a stochastic endowment $M_{t}^{D}$ and $M_{t}^{F}$ of its currency, so that $R_{t}=\left(Y_{t}^{D}, Y_{t}^{F}\right)$ defines the state vector of real endowments while $N_{t}=\left(M_{t}^{D}, M_{t}^{F}\right)$ defines the state vector of nominal endowments. Over time, real endowments and money stocks obey a multivariate stochastic process to be specified below. 
All consumers are identical in each country. The model is written from the perspective of the domestic country. The representative consumer has preferences characterized by:

$$
E t\left[\sum_{s=t}^{\infty} \beta^{s-t} U\left(c_{i s}^{D}, c_{i s}^{F}\right)\right] \quad 0<\beta<1
$$

where $c_{i s}{ }^{D}, c_{i s}{ }^{F}$ represent the consumption levels of the domestic and foreign goods by the representative agent of country $i$ over period $s$. We assume the utility function $U(.$, .) to be bounded, continuously differentiable, increasing in both arguments and strictly concave, $\beta$ being a constant time discount factor.

For simplicity, we consider preferences to be symmetric over both commodities, although that is not needed for the empirical analysis below. In equilibrium, agents will try to diversify risk by consuming half of the endowments in each country, so a pooling equilibrium will be reached. In such an equilibrium, the relative price, $p_{R}$, of $x^{F}$ in terms of $x^{D}$ when measured in units of $x^{D}$ per each unit of $x^{F}$, i.e., the real exchange rate, is obtained from Euler conditions,

$$
p_{R t}=\frac{U_{F}\left(Y_{t}^{D} / 2, Y_{t}^{F} / 2\right)}{U_{D}\left(Y_{t}^{D} / 2, Y_{t}^{F} / 2\right)}
$$

being equal to the marginal rate of substitution of consumption across commodities, and independent from nominal variables.

We assume that each economy is subject to cash in advance constraints. At the beginning of each period, consumers receive the endowment of currency in their own country. Since money does not produce any utility by itself, consumers will spend it to purchase the consumption commodities. However, to be able to purchase the foreign good, they first need to exchange currency through either spot or forward contracts at their corresponding equilibrium prices. From money market equilibrium, nominal prices must satisfy:

$$
\begin{aligned}
& P^{D}\left(R t, N_{t}\right)=M_{t}^{D} / Y_{t}^{D} \\
& P^{F}\left(R t, N_{t}\right)=M_{t}^{F} / Y_{t}^{F}
\end{aligned}
$$

which represent the well-known equations from the quantitative theory of money demand under a unit velocity of circulation of money.

Using the definition for the real exchange rate in (2) and (3) we can obtain the expression for the equilibrium spot exchange rate (in units of domestic currency per unit of foreign currency) satisfying the absence of arbitrage condition in the international market for goods (purchasing power parity)

$$
S_{t}=\frac{P_{t}^{D}}{P_{t}^{F}} p_{R t}=\frac{M_{t}^{D} Y_{t}^{F}}{M_{t}^{F} Y_{t}^{D}} \cdot \frac{U_{F}\left(Y_{t}^{D} / 2, Y_{t}^{F} / 2\right)}{U_{D}\left(Y_{t}^{D} / 2, Y_{t}^{F} / 2\right)}
$$

Equation (4) is typical of monetary models of exchange rate determination, where the exchange rate depends positively on the money supply and negatively on the real endowment of the own country, with relationships of opposite sign for the foreign country.

As an alternative, currency exchange can take place through forward contracts, which allow consumers to insure themselves against the uncertainty on the future purchasing power of their own currencies. We will assume that these contracts last a single period, being purchased at the end of each period. Hence, forward contracts determine the distribution of currency for the following period. To obtain the forward exchange rate (in units of domestic currency per units of foreign currency), we use an arbitrage condition similar to the covered interest rate parity.

Let us first consider the period $t$ price $b_{t}$ of a contract guaranteeing with certainty a unit of domestic currency at time $t+1$. The amount of commodity $x_{t+1}^{D}$ that can be purchased with a unit of domestic currency at time $t+1$ is the inverse of its price, which given the monetary and real endowments in the domestic country every period and the cash in advance restrictions, it is given by, 


$$
\frac{1}{P^{D}\left(R_{t+1}, N_{t+1}\right)}=\frac{Y_{t+1}^{D}}{M_{t+1}^{D}}=\pi_{t+1}^{D}
$$

At the margin, the utility from each of the $\pi^{D}{ }_{t+1}$ units of $x^{D}$ is given by $U_{D}\left(2 Y^{D}{ }_{t+1}, 2 Y^{F}{ }_{t+1}\right)$, which must be discounted by $\beta$ to obtain its equivalent in terms of time $t$ utility. So, the price in real terms of that contract, should be equal to the amount of commodity $x_{t}^{D}$ producing at time $t$ the same expected discounted utility than $\pi^{D}{ }_{t+1}$ units of commodity $x_{t+1}^{D}$ consumed at time $t+1, \mathrm{E}_{\mathrm{t}}\left[\beta \pi^{\mathrm{D}}{ }_{\mathrm{t}+1} \mathrm{U}_{\mathrm{D}}\left(2 \mathrm{Y}^{\mathrm{D}}{ }_{\mathrm{t}+1}, 2 \mathrm{Y}_{\mathrm{t}+1}\right)\right] / \mathrm{U}_{\mathrm{D}}\left(2 \mathrm{Y}^{\mathrm{D}}{ }_{\mathrm{t}}, 2 \mathrm{Y}^{\mathrm{F}} \mathrm{t}\right)$. Finally, the conversion to nominal units of the price of the contract is achieved by multiplying that real quantity times the price $P^{D}\left(R_{t}, N_{t}\right)$, or dividing by its inverse, $\pi_{\mathrm{t}}^{D}$. Hence, the price in domestic currency of a contract paying with certainty a unit of domestic currency at time $t+1$ is:

$b_{t}^{D}=E_{t}\left[\frac{\beta U_{D}\left(\frac{1}{2} Y_{t+1}^{D}, \frac{1}{2} Y_{t+1}^{F}\right) \pi_{t+1}^{D}}{U_{D}\left(\frac{1}{2} Y_{t}^{D}, \frac{1}{2} Y_{t}^{F}\right) \pi_{t}^{D}}\right]=E_{t}\left[q_{t+1}^{D}\right]$

where $q_{t+l}$ denotes the intertemporal marginal rate of substitution of consumption corrected by relative prices.

Similarly, we can compute the price in foreign currency of a contract paying with certainty one unit of foreign currency at time $t+1$. Using the absence of intertemporal arbitrage condition on commodity $x^{F}$, the price of that contract is, $b_{t}^{F}=E_{t}\left[\frac{\beta U_{F}\left(\frac{1}{2} Y_{t+1}^{D}, \frac{1}{2} Y_{t+1}^{F}\right) \pi_{t+1}^{F}}{U_{F}\left(\frac{1}{2} Y_{t}^{D}, \frac{1}{2} Y_{t}^{F}\right) \pi_{t}^{F}}\right]=E_{t}\left[q_{t+1}^{F}\right]$

where $q_{t+1}{ }^{F}$, is the analogue marginal rate of substitution corrected by relative prices, and $\pi^{F}{ }_{t}$ is the purchasing power of a unit of foreign currency in terms of $x^{F}$ at $t$.

Let us now consider two alternative investment strategies. The first one invests one unit of domestic currency on the riskless contract in that currency, with a risk-free return of $1 / b_{t}{ }^{D}$. The second strategy reproduces the covered purchasing power parity of interest rates by converting the domestic currency to foreign currency at the current exchange rate, $1 / S_{t}$, inverting that amount in a risk-free contract in that currency, with a return equal to $1 / b_{t}{ }^{F}$, to finally convert to domestic currency the proceeds of that investment through forward currency contracts at price $F_{t}^{t+1}$. In the absence of any risk other than the one emerging form the stochastic nature of endowments, investors must be indifferent between these two strategies, so that the absence of arbitrage condition implies the equivalence,

$$
\frac{1}{b_{t}^{D}}=\frac{F_{t}^{t+1}}{S_{t} b_{t}^{F}}
$$

Using (6) and (7) to eliminate $b_{t}^{D}$ and $b_{t}^{F}$, we can obtain the expression for the equilibrium forward exchange rate:

$$
F_{t}^{t+1}=S_{t} \frac{E_{t}\left[q_{t+1}^{F}\right]}{E_{t}\left[q_{t+1}^{D}\right]}
$$

Finally, we can characterize the risk premium in the foreign currency market by comparing expected returns from investments in foreign currency through spot and forward contracts. Taking conditional expectations on the future spot rate $S_{t+1}$ at (4) and subtracting the value of the forward rate $F_{t}^{t+1}$ from (9), we obtain the excess return in forward contracts, 


$$
E_{t}\left[S_{t+1}\right]-F_{t}^{t+1}=E_{t}\left[\frac{M_{t+1}^{D} Y_{t+1}^{F}}{M_{t+1}^{F} Y_{t+1}^{D}} \cdot p_{R}\left(R_{t+1}, N_{t+1}\right)\right]-\frac{M_{t}^{D} Y_{t}^{F}}{M_{t}^{F} Y_{t}^{D}} \cdot \frac{E_{t}\left[q_{t+1}^{F}\right]}{E_{t}\left[q_{t+1}^{D}\right]} \cdot p_{R}\left(R_{t}, N_{t}\right)
$$

Equation (10) shows that the expected excess return from a forward contract is determined by real and monetary variables, as well as by the preferences of the representative agents. These enter in (10) through the real exchange rate, $p_{R}$, and $q_{t}^{F}, q_{t}^{D}$. According to (2), (6) and (7), parameters in the utility function will determine the way how shocks in real and nominal endowments affect the risk premium. The risk premium emerges because of the fundamental uncertainty in the model, the uncertainty linked to the stochastic behavior of the economy. We want to bring into the model another source of uncertainty, related to the implementation of macroeconomic policy. To that extent, we now introduce the government in our model.

Let us suppose that there is in the domestic country a government which finances its expenditures through lumpsum taxes. Expenditures are defined as a constant fraction of real endowment, $G_{t}=\delta_{t} Y_{t}$, where $\delta_{t}$ may vary over time. The only effect of public expenditures is to reduce the level of resources available for the private sector to a level of $\left(1-\delta_{t}\right) Y_{t}$. By convenience, we will assume that the government collects taxes from its citizens once prices have been determined, but before commodities are exchanged between the two countries. ${ }^{2}$ As a consequence, in the previous expressions $\left(1-\delta_{t}\right) Y_{t}$ must substitute $Y_{t}$. The expression for the risk premium would then be given by (10), with state vectors now being defined as: $R_{t}$ $=\left[\left(1-\delta_{t}\right) Y_{t}^{D}, Y_{t}^{F}\right], R_{t+1}=\left[\left(1-\delta_{t+1}\right) Y_{t+1}^{D}, Y^{F}{ }_{t+1}\right]$.

\section{EMPIRICAL MODEL}

The characterization of risk premium in (10) is very general, and some additional structure must be introduced prior to testing the theory. We now incorporate into the model three assumptions which lead to a testable analytical formulation for the risk premium. First, we alter slightly the concept of risk premium, to avoid some practical difficulties. Secondly, we specify the preferences of the representative consumer, since they play a central role in the determination of the risk premium. Finally, we make some assumptions on the stochastic behavior of the variables in the model.

\subsection{Redefining The Risk Premium}

The definition of risk premium in (10) is not invariant to changes in the units of measurement. Specifically, it is subject to Siegel paradox, as a consequence of Jensen's inequality. The value of the risk premium emerging from this expression is different depending on whether we measure the exchange rate in units of domestic currency per unit of foreign currency $\left(S_{t}\right)$, or the reverse $\left(1 / S_{t}\right)$. To avoid this problem, it is standard in the literature to use a definition of risk premium that incorporates a logarithmic transformation, since then the change of units only affects the sign of the risk premium: $E_{t}\left[\ln \left(1 / S_{t+1}\right)\right]=-E_{t}\left[\ln \left(S_{t+1}\right)\right]$. If we represent by $s_{t+1}$ the $\log$ of $S_{t+1} / S_{t}$ (the depreciation rate of the domestic currency), and by $f_{t}^{t+1}$ the log of $F_{t}^{t+1} / S_{t}$ (the depreciation rate of the exchange rate insurance or forward premium), we can define the new measure of risk premium as $E_{t}\left[s_{t+1}-f_{t}^{t+1}\right]$. Using the approximation $\ln (1+x) \approx x$ for a small $x$, this measure is related to the risk premium in (10) through: $E_{t}\left[s_{t+1}-f_{t}^{t+1}\right] \approx E_{t}\left[\left(S_{t+1}-F_{t}^{t+1}\right) / S_{t}\right]$. Therefore, the new formulation of the risk premium is approximately equal to the excess return in the forward rate, as a percentage.

\subsection{Consumer Preferences}

As a standard illustration, we assume a Cobb-Douglas utility function, ${ }^{3}$

$U\left(c_{i t}^{D}, c_{i t}^{F}\right)=\frac{\left[\left(c_{i t}^{D}\right)^{\alpha}\left(c_{i t}^{F}\right)^{1-\alpha}\right]^{(1-v)}}{(1-v)} \quad 0 \leq \alpha \leq 1 \quad v \geq 0$ y $v \neq 1$

\footnotetext{
${ }^{2}$ Depending on the timing of exchanges, fiscal policy might affect prices and produce asymmetries in consumption in both countries.

${ }^{3}$ Strictly speaking, a Cobb-Douglas utility is compatible with a pooling equilibrium solution only when $\alpha=1 / 2$.
} 
where $v$ is the risk aversion parameter. Using this function into expression (4) for the spot exchange rate and taking into account macroeconomic policy, we obtain the depreciation rate for domestic currency, ${ }^{4}$

$$
\frac{S_{t+1}}{S_{t}}=\frac{\left(1-\delta_{t+1}\right)}{\left(1-\delta_{t}\right)} \frac{M_{t+1}^{D}}{M_{t}^{D}}\left(\frac{M_{t+1}^{F}}{M_{t}^{F}}\right)^{-1}
$$

Because of the homogeneity of the Cobb-Douglas function and our choice of a pooling equilibrium solution, the vector of states for real endowments does not enter into this expression, with economic policy showing up through $1-\delta_{t}$. Under Cobb-Douglas preferences, real endowments affect the relative price and the price index equally but with an opposite sign, so that their effects on the spot rate cancel out. On the contrary, the macroeconomic policy variable $\delta_{t}$ affects just the relative price through the effect of real endowment on marginal utility. By construction, this variable does not influence the price index, which depends on global endowments $Y_{t}^{D}, Y_{t}^{F 5}$.

To obtain a similar expression for forward exchange rates, we must use the Cobb-Douglas utility function in equations (6) and (7), which characterize the mathematical expectations of the price corrected marginal rates of intertemporal substitution in the two currencies, $E_{t}\left[q_{t+1}^{F}\right], E_{t}\left[q_{t+1}^{D}\right]$, whose ratio is, according to (9) the forward premium,

$$
\frac{F_{t}^{t+1}}{S_{t}}=\frac{E_{t}\left[q_{t+1}^{F}\right]}{E_{t}\left[q_{t+1}^{D}\right]}=\frac{E_{t}\left[\beta\left(\frac{1-\delta_{t+1}}{1-\delta_{t}}\right)^{\alpha(1-v)}\left(\frac{Y_{t+1}^{D}}{Y_{t}^{D}}\right)^{\alpha(1-v)}\left(\frac{Y_{t+1}^{F}}{Y_{t}^{F}}\right)^{(1-\alpha)(1-v)}\left(\frac{M_{t+1}^{F}}{M_{t}^{F}}\right)^{-1}\right]}{E_{t}\left[\beta\left(\frac{1-\delta_{t+1}}{1-\delta_{t}}\right)^{(\alpha-1)-v \alpha}\left(\frac{Y_{t+1}^{D}}{Y_{t}^{D}}\right)^{\alpha(1-v)}\left(\frac{Y_{t+1}^{F}}{Y_{t}^{F}}\right)^{(1-\alpha)(1-v)}\left(\frac{M_{t+1}^{D}}{M_{t}^{D}}\right)^{-1}\right]}
$$

Finally, we would take the conditional expectation in (12) and subtract the previous expression to obtain the risk premium, as defined in section 3.1, $E_{t}\left[S_{t+1} / S_{t}\right]-F_{t}^{t+1} / S_{t}$. But before we obtain a tractable expression for the risk premium, it is necessary to make some assumptions on the joint stochastic behavior of real and nominal endowments, which relate to the fundamental uncertainty, as well as on the probability distribution of fiscal variable $\delta_{\mathrm{t}}$, which is related to policy uncertainty.

\subsection{The Stochastic Process For The Main Variables}

The risk premium depends on conditional expectations of cross products of random variables. Under general conditions, these products do not have a well defined probability distribution which might allow for computing their expectations, and we need to incorporate some restrictions on the stochastic behavior of the main variables in the model. That will also allow us to find a formulation for the risk premium as a function of the main sources of uncertainty in the economy.

\footnotetext{
${ }^{4}$ Cole and Obstfeld (1991) show that the efficient allocations of resources in an economy like the one considered in this paper is of the form:

$$
\begin{aligned}
& c_{D t}^{D}=\theta_{1} Y_{t}^{D} \Rightarrow c_{F t}^{D}=\left(1-\theta_{1}\right) Y_{t}^{D} \\
& c_{D t}^{F}=\theta_{1} Y_{t}^{F} \Rightarrow c_{F t}^{F}=\left(1-\theta_{1}\right) Y_{t}^{F}
\end{aligned}
$$

It is simple to see that when these consumption expressions are plugged into (6) proportionality factors in the consumption rules cancel out, leading exactly to the same expression (12). That means that, so long as countries are following efficient consumption allocations, the exchange rate will be determined by the same fiscal and monetary policy indicator that appear in (12).

${ }^{5}$ Let us assume that real and nominal endowments, $Y, M$, are constant for the two countries. According to (3), this implies that the price indices $P^{D}, P^{F}$, will also be constant. An increase in the proportion defining public expenditures, $\delta_{t+1}>\delta_{t}$ will reduce the amount $x$ of commodity available for private consumption, thereby reducing the relative price of $x^{F}, p_{R}$. Hence, the spot exchange rate decreases, producing a appreciation in the domestic currency.
} 
We will assume independence between fundamental uncertainty and macroeconomic policy uncertainty. With regard to fundamental uncertainty, we will assume, as in $\mathrm{Hu}$ (1992), that, conditional on available information, growth rates in the fundamental variables $\left(m_{t+1}^{i}=M_{t+1}^{i} / M_{t}^{i}, y_{t+1}^{i}=Y_{t+1}^{i} / Y_{t}^{i} ; i=D, F\right)$ follow a joint lognormal distribution given by:

$$
\left(\begin{array}{c}
\log m_{t}^{i} \\
\log y_{t}^{i}
\end{array}\right) / I_{t-1} \sim N\left(\left(\begin{array}{c}
\mu_{m_{t}^{i}} \\
\mu_{y_{t}^{i}}
\end{array}\right),\left(\begin{array}{cc}
\sigma_{m_{t}^{i}}^{2} & \sigma_{m_{t}^{i} y_{t}^{i}} \\
\sigma_{m_{t}^{i} y_{t}^{i}} & \sigma_{y_{t}^{i}}^{2}
\end{array}\right)\right)
$$

We assume that money supply and production are not correlated between the two countries. Relative to policy uncertainty, we will assume policy decisions to be independent of the state of the economy. To represent the stochastic behavior of economic policy we follow a similar strategy to that of the so-called Peso problem. The policy indicator $\delta_{t}$, i.e, . the ratio of domestic public expenditures to the endowment of the own country, $G_{t}=\delta_{t} Y_{t}^{D}$, may follow one of two possible regimes: $\delta_{0}, \delta_{1}$, with $\delta_{0}>\delta_{1}$.

Currency risk prior to constitution of the European Union is related to uncertainty on the self-discipline of governments to follow rigorous policies. So, we consider governments following initially expansive policies, with $\delta_{t}=\delta_{0}$, and focus on the market estimate of $p_{t}=\operatorname{Prob}\left(\delta_{t+1}=\delta_{1} / \delta_{t}=\delta_{0}\right)$, the probability that there might be a change in policy next period, from expansive to restrictive. That would amount to the perception that the government is following the kind of rigorous policy that could allow for fulfilling the deficit and debt convergence criteria established in the Maastricht agreement. That probability should be expected to change over time as a function of the evolution of some economic indicators that agents consider relevant when predicting future policy decisions. The probability that an expansionary state lasts for at least one more period is 1- $p_{t}=\operatorname{Prob}\left(\delta_{t+1}=\delta_{o} / \delta_{t}=\delta_{0}\right)$. The conditional expectation of the economic policy indicator, $\delta_{\mathrm{t}+1}$, is: $E_{t}\left[\delta_{t+1}\right]=p_{t} \delta_{1}+\left(1-p_{t}\right) \delta_{0}$, and its variance: $\operatorname{Var}_{t}\left(\delta_{t+1}\right)=p_{t}\left(1-p_{t}\right)\left(\delta_{1}-\delta_{0}\right)^{2}$.

\subsection{Expressions For The Risk Premium}

Expression (12) for the depreciation rate of the spot exchange rate can be written,

$$
\frac{S_{t+1}}{S_{t}}=\frac{1-\delta_{t+1}}{1-\delta_{t}} \frac{M_{t+1}^{D}}{M_{t}^{D}}\left(\frac{M_{t+1}^{F}}{M_{t}^{F}}\right)^{-1}=g_{t+1} m_{t+1}^{D}\left(m_{t+1}^{F}\right)^{-1}
$$

Where $\mathrm{g}_{\mathrm{t}+1}=\left(1-\delta_{\mathrm{t}+1}\right) /\left(1-\delta_{\mathrm{t}}\right)$ is the growth rate of the fraction of real endowments available to the consumer. We will have $g_{t+1}=\left(1-\delta_{1}\right) /\left(1-\delta_{0}\right)=k$, with probability $p_{t}$ (regime change) and $g_{t+1}=\left(1-\delta_{0}\right) /\left(1-\delta_{0}\right)=1$ with probability $1-p_{t}($ same regime).Taking conditional expectations under the previous assumptions, ${ }^{6}$

$$
E_{t}\left[\ln \left(S_{t+1} / S_{t}\right)\right]=E_{t}\left[\ln \left(g_{t+1}\right)+\ln \left(m_{t+1}^{D}\right)-\ln \left(m_{t+1}^{F}\right)\right]=\ln (k) p_{t}+\mu_{m_{t+1}^{D}}-\mu_{m_{t+1}^{F}}
$$

since the three terms are independent from each other.

Under the stochastic independence between fundamental and policy variables, expression (13) for the forward premium becomes:

$$
\frac{F_{t}^{t+1}}{S_{t}}=\frac{E_{t}\left[q_{t+1}^{F}\right]}{E_{t}\left[q_{t+1}^{D}\right]}=\frac{E_{t}\left[g_{t+1}^{\alpha(l-v)}\right] E_{t}\left[\left(y_{t+1}^{D}\right)^{\alpha(l-v)}\left(y_{t+1}^{F}\right)^{(l-\alpha)(l-v)}\left(m_{t+1}^{F}\right)^{-1}\right]}{E_{t}\left[g_{t+1}^{(\alpha-l)-\alpha v}\right] E_{t}\left[\left(y_{t+1}^{D}\right)^{\alpha(l-v)}\left(y_{t+1}^{F}\right)^{(l-\alpha)(l-v)}\left(m_{t+1}^{D}\right)^{-l}\right]}
$$

${ }^{6} E_{t}\left[\ln \left(g_{t+1}\right)\right]=\ln (k) p_{t}+\ln (1)\left(1-p_{t}\right)=\ln (k) p_{t}$ 
Using properties of the lognormal distribution as in $\mathrm{Hu}$ (1997), substituting expressions for the conditional expectations $^{7}$ and simplifying, we get, ${ }^{8}$

$$
\begin{aligned}
& \frac{F_{t}^{t+1}}{S_{t}}=\frac{k^{\alpha(1-v)} p_{t}+\left(1-p_{t}\right)}{k^{\alpha(1-v)-1} p_{t}+\left(1-p_{t}\right)} \exp \left(\mu_{m_{t+1}^{D}}-\mu_{m_{t+1}^{F}}\right) x \\
& \exp \left(\frac{1}{2} \sigma_{m_{t+1}^{F}}^{2}-\frac{1}{2} \sigma_{m_{t+1}^{D}}^{2}+\alpha(1-v) \sigma_{y} D{ }_{t+1}^{D} m_{t+1}^{D}-(1-\alpha)(1-v) \sigma_{y_{t+1}}^{F} m_{t+1}^{F}\right)
\end{aligned}
$$

Finally, we subtract from (15) expression (17) after taking logs, to analytically characterize the risk premium,

$$
\begin{gathered}
E_{t}\left[s_{t+1}-f_{t}^{t+1}\right]=E_{t}\left[\ln \left(S_{t+1}\right)-\ln \left(F_{t}^{t+1}\right)\right]= \\
=\ln (k) p_{t}-\ln \left(\frac{k^{\alpha(1-v)} p_{t}+\left(1-p_{t}\right)}{k^{\alpha(1-v)-1} p_{t}+\left(1-p_{t}\right)}\right)+\frac{1}{2} \sigma_{m_{t+1}^{D}}^{2}-\frac{1}{2} \sigma_{m_{t+1}^{F}}^{2} \\
-\alpha(1-v) \sigma_{y_{t+1}^{D} m_{t+1}^{D}}+(1-\alpha)(1-v) \sigma_{y_{t+1}^{F} m_{t+1}^{F}}
\end{gathered}
$$

This expression for the exchange rate risk premium contains a distinct component for each source of uncertainty in the theoretical model. The first one, associated to macroeconomic policy uncertainty, is a nonlinear function of $p_{t}$. To better understand the effect on the risk premium of changes in $p_{t}$, we simulated the $f\left(\delta_{0}, \delta_{1}, p_{t}\right)=\ln (k) p_{t}-\ln \left(\frac{k^{\alpha(l-v)} p_{t}+\left(1-p_{t}\right)}{k^{\alpha(l-v)-1} p_{t}+\left(1-p_{t}\right)}\right)$ function and the conditional variance of the binomial distribution chosen to represent the stochastic behavior of fiscal policy, $g\left(\delta_{0}, \delta_{1}, p_{t}\right)=\operatorname{var}_{t}\left(\delta_{t+1}\right)=p_{t}\left(1-p_{t}\right)\left(\delta_{1}-\delta_{0}\right)^{2}$, for given values of the utility function parameters $\alpha, v$. Standardized versions of both functions in Figure $1^{9}$ display a very similar behavior for any given value of the risk aversion coefficient, so that the volatility of fiscal policy and the size of the risk premium are related to each other. Hence, as a first approximation, it can be assumed that $\exists \lambda>0$ such that $f\left(\delta_{0}, \delta_{1}, p_{t}\right) \cong \lambda g\left(\delta_{0}, \delta_{1}, p_{t}\right), \forall\left(\delta_{0}, \delta_{1}, p_{t}\right)$ and consider the transformed expression for the risk premium,

$$
\begin{gathered}
E_{t}\left[s_{t+1}-f_{t}^{t+1}\right]=\lambda p_{t}\left(1-p_{t}\right)\left(\delta_{0}-\delta_{1}\right)^{2}+\frac{1}{2} \sigma_{m_{t+1}^{D}}^{2}-\frac{1}{2} \sigma_{m_{t+1}^{F}}^{2}+ \\
-\alpha(1-v) \sigma_{y_{t+1}^{D} m_{t+1}^{D}}+(1-\alpha)(1-v) \sigma_{y_{t+1}^{F} m_{t+1}^{F}}
\end{gathered}
$$

In this expression, we would expect a positive sign for $p_{t}$, and a negative sign for $p^{2}$. The risk premium is zero when $p_{t}$ is either 0 or 1 , reflecting absolute certainty on the fiscal regime. The effect of $p_{t}$ on the premium reaches its maximum value for intermediate values of $p_{t}$. When $p_{t}<1 / 2$, an increase in probability will increase fiscal policy uncertainty, with a positive effect on the risk premium, while for $p_{t}>1 / 2$, a probability increase would reduce uncertainty and the risk premium.

${ }^{7} E_{t}\left[g_{t+1}^{\alpha(1-v)}\right]=k^{\alpha(1-v)} p_{t}+\left(1-p_{t}\right)$.

${ }^{8}$ Following $\mathrm{Hu}$ (1997) we assume that there are interactions between the real and nominal variables in a economy, a fact which arises in the empirical analysis we perform below. However, it is far from evident that lognormality of $\emptyset \log \left(m_{t}\right)$ and $\nabla \log \left(y_{t}\right)$ guarantees that their product is also lognormal if this variables are conditionally correlated. In Hodrick (1989) fundamentals are assumed to be conditionally uncorrelated. In that case expression (17) would be given by:

$\frac{F_{t}^{t+l}}{S_{t}}=\frac{k^{\alpha(l-v)} p_{t}+\left(1-p_{t}\right)}{k^{\alpha(1-v)-1} p_{t}+\left(1-p_{t}\right)} \exp \left(\mu_{m_{t+1}^{D}}-\mu_{m_{t+1}^{F}}^{F}\right) \exp \left(\frac{1}{2} \sigma_{m_{t+1}}^{F}-\frac{1}{2} \sigma_{m_{t+1}^{D}}^{2}\right)$

${ }^{9}$ Figures and tables are included in a separated appendix available upon request or on http://www.ucm.es/info/ecocuan/jajm 
The second part of the expression reflects the response of the risk premium to business cycle uncertainty, a function of the conditional variances of domestic and foreign money supply, $\sigma_{m_{t+1}^{D}}^{2}, \sigma_{m_{t+1}^{F}}^{2}$, and their conditional covariances with real endowments, $\sigma_{y_{t+1}^{D} m_{t+1}^{D}} y \sigma_{y_{t+1}^{F} m_{t+1}^{F}}$. These terms can be explained through their contribution to the volatility of the purchasing power parity of both currencies given the cash in advance constraints.

An increase in volatility of nominal or real endowments in the domestic country, or a decrease in their covariance, increases the volatility of the purchasing power of the domestic currency. Risk averse foreign consumers will then be willing to pay a premium to guarantee themselves a future price for the domestic currency through a forward contract, and the forward exchange rate, $F_{t}^{t+1}$, measured in units of domestic currency per unit of foreign currency will decrease. An increase in the volatility of nominal or real endowments for the foreign country or a decrease in their joint covariance would have the opposite effects on the forward exchange rate $F_{t}^{t+1}$, which would then increase.

\section{EMPIRICAL TEST OF THE RISK PREMIUM}

To test (19) we use a two step estimation strategy: first, we estimate the probability that convergence takes place and we obtain the conditional variances and covariances for the exogenous variables. ${ }^{10}$ Second, we use that information to estimate (19) by OLS, applying standard specification tests. The constant term in the regression acts as a proxy for the set of second order conditional moments which are not time varying. Since fundamental variables are measured differently in each country, their volatilities are not directly comparable, so it is not possible to estimate the model under the constraints imposed by international symmetry. Hence, we only estimate the unrestricted version of the model, which incorporates all conditional moments separately. Testing the theory then consists on testing for significance and sign on estimated parameters.

\subsection{A Proxy For The Probability For A Regime Change}

The exchange rate risk premium in (19) depends on the perceived probability of a change from a somewhat loose to a more rigorous policy. Even though the probability of a change in regime in the theoretical model, $p_{t}$, refers just to a possible change in the level of public expenditures, we can extend the concept to capture any change in policy which might end up affecting either the level or the volatility of fundamental variables.

To substitute for the unobserved convergence probability assigned by the financial markets to the event that the country belongs to the EMU by January 1999, we use a procedure similar to JP Morgan EMU calculator. The basic feature of the EMU calculator is that the observed interest rate spread at time $t, I R \_S P R$, is supposed to be a weighted average of the $I N$ spread, $I R \_S P R^{I N}$, which would apply if the country adopts the single currency, and the $O U T$ spread, $I R \_S P R^{O U T}$, corresponding to the case when the country is out of the EMU. The weights are the corresponding probabilities of each event,

$$
I R_{-} S P R_{t}=p_{t} I R_{-} S P R_{t}^{I N}+\left(1-p_{t}\right) I R_{-} S P R_{t}^{\text {OUT }}
$$

In a monetary union, financial instruments from different countries with the same maturity, liquidity and credit risk must have the same yield. So, if on January 1999 the country fulfils the convergence criteria ${ }^{11}$ and enters into the

\footnotetext{
${ }^{10}$ We consider the bilateral relationships between Spanish peseta (SPA), Deutsche mark (DEM), Sterling pound (GBP) and French franc (FRF). The sample starts on January 1, 1986, after Spain became a member of the European Economic Community, and ends in April 1998 (In May 1998 the European Council announced the countries that would form the euro area on January the $1^{\text {st }}$, 1999). We use monthly data for Spain (SP), Germany (GER), France (FR) and United Kingdom (UK). The industrial production index (IPI) is used as indicator of economic activity, and M2 as the monetary aggregate. To compute probabilities of convergence, we use interest rates for swaps at 3-year maturities for all countries, over 1992:1 to 1998:04. Finally, spot and forward exchange rates represent the value for the last day of the month. Preliminary data analysis (unit root tests and intervention analysis [Box and Tiao (1975)]) shows that all variables, but risk premium, are I(1). Therefore, all variables are differenced in the model for the conditional variance. These results are not reported here, but are available upon request.

${ }_{11}$ To enter EMU, the Maastricht Treaty indicates that candidates must lower inflation to within $1.5 \%$ of the lowest three in the European Community, push budget deficits below 3\% of GDP, lower debt-to-GDP ratios to 60\%, and maintain a stable currency
} 
EMU, its riskless interest rate should be equal to those in the other countries in the monetary union. On the other hand, if the country does not enter the union, its interest rate will be determined by a variety of factors including its own monetary policy and it will generally maintain a positive spread relative to countries in the union. Hence, if $I R_{-} S P R_{t}^{I N}=0$ and $I R \_S P R_{t}^{O U T}=\theta>0$ in $(20)$, we can estimate the probability assigned by the financial markets at time $t$ to the event that the country belongs to the EMU by January 1999:

$$
p_{t}=1-I R_{-} S P R_{t} / \theta
$$

In fact, we will later use in estimation a more flexible functional form by taking (21) to suggest a negative relationship between the convergence probability and the interest rate swap:

$$
p_{t}=\alpha_{0}-\alpha_{1} I R_{-} S P R_{t}
$$

then

$$
p_{t}\left(1-p_{t}\right)=\left(\alpha_{0}-\alpha_{1} I R_{-} S P R_{t}\right)-\left(\alpha_{0}-\alpha_{1} I R_{-} S P R_{t}\right)^{2}
$$

so that (19) becomes a regression equation of the form,

$$
\begin{aligned}
& P R M_{t}=\ln \left(\frac{S_{t+1}}{F_{t}^{t+1}}\right)=\beta_{0}+\beta_{1} I R_{-} S P R_{t}+\beta_{2} I R_{-} S P R_{t}^{2}+ \\
& +\beta_{3} \sigma_{m_{t+1}^{D}}^{2}+\beta_{4} \sigma_{m_{t+1}^{F}}^{2}+\beta_{5} \sigma_{y_{t+1}^{D} m_{t+1}^{D}}+\beta_{6} \sigma_{y_{t+1}^{F} m_{t+1}^{F}}+u_{t} \\
& \text { with } h=\lambda\left(\delta_{0}-\delta_{1}\right)^{2} ; \quad \beta_{0}=h \alpha_{0}\left(1-\alpha_{0}\right) ; \quad \beta_{1}=-h \alpha_{1}\left(1-2 \alpha_{0}\right) ; \quad \beta_{2}=-h \alpha_{1}^{2} ; .
\end{aligned}
$$

Which includes the excess return in forward contracts $\left(\mathrm{PRM}_{\mathrm{t}}\right)$, defined as $\ln \left(\mathrm{S}_{\mathrm{t}+1}\right)-\ln \left(\mathrm{F}_{\mathrm{t}}^{\mathrm{t+1}}\right)$, as dependent variable, projected on a constant and the interest rate spread $\left(I R \_S P R\right)$ approximating the probability of a change in regime. The square value of the proxy for the convergence probability is also included in the model with an expected negative sign as discussed above, as opposed to the positive expected sign of $I R \_S P R$. The risk premium expression also includes conditional variances $\left(\begin{array}{lll}\sigma^{2}{ }_{m_{t+1}^{D}}^{D}, & \sigma^{2}{ }_{m_{t+1}^{F}}^{F}\end{array}\right)$ and covariances, $\left(\begin{array}{ll}\sigma_{y_{t+1}^{D} m_{t+1}^{D}}^{D}, & \sigma_{y_{t+1}^{F} m_{t+1}^{F}}\end{array}\right) .^{12}$

The unquestionable participation of Germany in the euro area makes it reasonable to focus the analysis on differentials with German interest rates. Therefore, the probability of the country adopting the single currency from the outset of the EMU is inversely related to the spread of interest rates with Germany. We consider interest rates from swap markets to be more reliable than those from the market for government bonds, which is rather narrow and illiquid in some countries. Furthermore, the tax treatment of returns on public debt is different across countries. On the contrary, the swap market is very liquid and contracts are standardized across currencies, including the tax treatment of returns, and they are not affected by default risk. ${ }^{13}$ Using the spread of 3-year swap rate as a proxy for the probability of convergence is based on our belief that it is the maturity most likely to capture expectations of convergence to the euro area for a country. Its behavior is similar to those of the 5- and 10-year rates, while the 1-year rate is very influenced by monetary policy decisions.

Interest rate spread with Germany and risk premium values for France, Spain and United Kingdom are shown in Figure 2, for the 1994:01-1998:04 period. In all cases, the risk premium series is clearly more volatile than the spread. Over 1994 and the first part of 1995, the spread increased for Spain, sharply decreasing during 1996, which could reflect a

\footnotetext{
${ }^{12}$ To estimate conditional variances and covariances we assume real and monetary variables, represented by the money supply and industrial production, follow a joint lognormal distribution, and also that their dynamics can be summarized by a VARMA model in logged differences with GARCH innovations, which allows us to capture any possible nonlinear dependence among their innovations, as proposed by Bollerslev (1986) and Baba, Engle, Kraft and Kroner (1991), among many others. We estimated heteroskedastic effects for the money supply in France and the UK and the covariance between money supply and industrial production in France. However, we also obtain a statistically significant autoregressive structure for the conditional covariance between both variables in Spain and Germany. No conditional heteroskedasticity in the variances of the money supply or industrial production was found for these two countries. A detailed explanation of the estimation process is available upon request.

${ }^{13}$ Extracting market expectations on a given event from asset prices is a question which has recently attracted a great deal of interest [see Dillen and Edlund (1997), Favero et al. (2000), for recent reviews see Söderlind and Svensson (1997), and Bates (1998)].
} 
growing probability that this country could adopt the single currency from the beginning. There was a transitory increase at the beginning of 1997, the spread returning very quickly to a decreasing path. The spread with France widened in the spring of 1995, from zero to about 1 percentage point, remaining at that level until the end of 1996, when it fell back to zero. This is consistent with a high probability of this country adopting the single currency from the start. On the other hand, the spread shown a rising trend since the beginning of 1994 for the United Kingdom, stabilizing after 1996, but without the sharp decrease observed for Spain and France. These graphs suggest that for Spain and France, an increase in IR_SPR, i.e. a loss in market confidence, induces an increase in the volatility of the risk premium. However, for the United Kingdom, the Figure could conceivably indicate that the United Kingdom was not considered to be a likely participant in the EMU, and the correlation between spread and risk premium is more difficult to explain.

\subsection{The Effect Of Uncertainty On The Risk Premium}

We first present in Table 2 least-squares estimates of (23) for the full sample, 1986:02-1998:04, and for the three bilateral relationships without taking into account the effect of uncertainty on policy implementation, so that conditional second order moments are the only explanatory variables. This sample exploits all available data on conditional second order moments. Using risk premium data corrected from extreme values sharply decreases the evidence of residual autocorrelation. $\mathrm{R}^{2}$ values are rather low, although estimated parameters show their right sign, when significant, but the overall suggestion is that macroeconomic uncertainty may not be the most important factor determining risk premium in exchange rates.

Alternatively, we studied the explanatory power of policy uncertainty, as measured by the two spread variables. Using the longer available sample for interest rate swaps, 1992:02-1998:04, we obtained a poor fit, probably because of including the period prior to formal approval of the Union Treaty. Convergence criteria were adopted in the European Union Treaty, which was approved at the European Council celebrated at Maastricht in February 1992, although their final approval at the level of the Congress of each country took up to November 1993. Hence, from 1992, governments considered the possibility of implementing policy with a goal of achieving convergence, although it is just from 1994 that convergence criteria had a formal validity.

When the shorter period, 1994:01 - 1998:04, is considered in Table 3, results become much more satisfactory in terms of explanatory power as well as significance and sign of individual coefficients. Simple and adjusted $\mathrm{R}^{2}$ coefficients fall between $10 \%$ and $15 \%$, well above their values for the longer sample. The interest rate spread is statistically significant except for the GBP/GEM relationship. In this case, lack of significance seems to be a consequence of colinearity between the two interest rate spread variables. A Wald test for joint significance of both variables confirms this result. The sign of the coefficients is as expected, except for the GBP/GEM exchange rate, suggesting that the linear probability term would not capture adequately all the information regarding the risk premium in that currency. It seems clear that it is only from 1994 that policy uncertainty becomes a relevant factor in the time evolution of the risk premium for these currencies.

We present in Table 4 the estimation results for the full model, for the 1994:01-1998:04 period, including macroeconomic as well as policy uncertainty variables to determine the risk premium. Conditional second order moments of fundamental macroeconomic variables are generally not significant. On the contrary, policy uncertainty variables are always significant and show the expected sign according to the theoretical model, as explained above. The left column in Figure 3 shows, for the 1994:01-1998:04 period, the actual exchange risk premium (which was also shown in Figure 2) and the fitted value from the model in Table 4 . The middle and right columns show the contribution to the fitted risk premium of every block of regressors, macroeconomic uncertainty: $\hat{\beta}_{3} \sigma_{m_{t+1}^{D}}^{2}+\hat{\beta}_{4} \sigma_{m_{t+1}^{F}}^{2}+\hat{\beta}_{5} \sigma_{y_{t+1}^{D} m_{t+1}^{D}}+\hat{\beta}_{6} \sigma_{y_{t+1}^{F} m_{t+1}^{F}}$, (middle column) and fiscal policy $\hat{\beta}_{2} I R_{-} S P R_{t}+\hat{\beta}_{3} I R_{-} S P R 2_{t}$, (right column). Next, we present, in Figure 5 a scatter diagram for the fitted risk premium versus ( $i$ ) observed exchange risk premium (left column) (ii) the macroeconomic uncertainty contribution (middle column) and (iii) the policy uncertainty contribution (right column). An inspection of these diagrams reveals that the risk premium is extremely volatile and it is more closely related to policy uncertainty than to macroeconomic uncertainty. That is also reflected in correlations coefficients between each variables with fitted risk premium, which are significantly higher for policy uncertainty (among 0.70 and 0.93 ) than for the macroeconomic uncertainty (among 0.19 and 0.58 ). 
The general conclusion is that it is the uncertainty on future policy decisions, much more than that on the fundamentals of the economy, which determine the level of the risk premium. Furthermore, this evidence arises only after 1994, suggesting that it was the formal approval of the Maastricht criteria, more than the Maastricht agreement itself, the starting point for the exchange rate markets to incorporate the probability of convergence into the determination of risk premium.

\subsection{Numerical Estimates Of Convergence Probabilities}

The approach we have followed to extract information from the interest rate spread on the probability that a country joins the European Monetary Union at April 1999 allows us to estimate the time evolution of these probabilities. From the estimation of (23) in Table 4 we can recover estimates ${ }^{14}$ for the probabilities that France, Spain and UK belong to the euro area in April 1999. These estimated probabilities of joining the EMU, normalized so that $p_{t} \in[0,1]$, are shown in Figure 4. The results look fairly reasonable. For Spain as well as France the value of the indicator rose since of beginning of 1996. The upward trend confirms the current perception of an increased probability that Spain and France would adopt the single currency from the outset of the EMU. The United Kingdom had a high probability of entering the EMU during late 1993, but it collapsed during the general wave of pessimism on the future of a currency union during 1994. Since then, the probability continuously decreased until the end of 1997, suggesting, as it was finally the case, that the likelihood of this country participating in the euro area was not considered to be particularly great.

\section{CONCLUSIONS}

We have proposed a general equilibrium model to characterize the risk premium in the exchange rate market as a function of economic uncertainty. Our main contribution is the distinction between two types of uncertainty, one associated to the cyclical behavior of the economy, the other one produced by anticipation of possible changes in economic policy. The later shows up in our estimates as an essential factor in the behavior of financial markets over the convergence process to the common European currency. Interest rate spreads and squared spread values, used as proxies for the amount of policy uncertainty have an acceptable significant power in the later 1994-1998 period, once national Parliaments approved the Maastricht criteria. Regarding fundamental uncertainty, the relevance of conditional variances of money supply and industrial production as well as the conditional covariance between these two variables is rather limited, in consistency with the results reached by previous authors. There are no significant differences in the behavior of the risk premium for the bilateral relationships considered, except in the one involving the sterling pound, most likely due to the fact that the UK declined entering the euro zone at an initial stage.

Results in this paper should be taken as a starting point for further research. A more detailed estimation of conditional variances and covariances of real and nominal factors in the economy, as well as a better characterization of the uncertainty on fiscal policy might be useful towards better explaining risk premium in currency markets. Nonseparable preferences would lead to rather complex equilibrium conditions without closed form solution. Numerical solution methods that parameterize conditional expectations might allow us to produce simulated time series from which the effects of fundamental and policy uncertainty on exchange rate risk premium might be studied. This is left for further research.

\section{ACKNOWLEDGEMENT}

We are grateful to R. Flores, G. Kaminsky, and A. Novales for helpful comments. We would like to acknowledge the financial support of the Ministerio de Educación, Spain trough project BEC2003-03965. J. A. Jimenez-Martin is Visiting scholar at the Department of Economics, George Washington University thank to the financial support of the Fundación Caja Madrid and Univesidad Complutense of Madrid.

\footnotetext{
14 From the estimation of (23) in Table 4 we can recover estimates for $\alpha_{0}, \alpha_{1}$ and $h$. The system of equations listed in (23) does not have an analytical solution and we need to use a numerical method to solve it in MATLAB. Then, from (22), it is straightforward to compute the convergence probabilities
} 


\section{REFERENCES}

1. Baba, Y., Engle R., Kraft D., and Kroner, K. 1991. Multivariate simultaneous generalized ARCH, Economics Working Paper Series 89-57r, Department of Economics, UC San Diego.

2. Banerjee, A., Lumsdaine, R., and Stock, J. 1992. Recursive and sequential tests of the unit-root and trendbreak hypothesis: theory and international evidence, Journal of Business \& Economic Statistics, 10, 271-287.

3. Bates, D. S. 1998. Financial Markets' assessment of EMU, paper presented at the Carnegie-Rochester Conference, November.

4. Bekaert, G. and Hodrick, R. J. 1992. Characterizing predictable components in excess returns on equity and foreign exchange markets, Journal of Finance, 47, 467-510.

5. Bollerslev, T. 1986. Generalized autoregressive conditional heteroskedasticity, Journal of Econometrics, 31, 307-327.

6. Borensztein, E. 1987. AAlternative hypotheses about the excess return of dollar assets@, International Monetary Fund Staff Papers, 34, 29-59.

7. Box, G. E. P. and Tiao, G. C. 1975. Intervention Analysis with applications to economic and environmental problems, Journal of American Statistical Association, 70, 70-79.

8. Cole, H. and Obstfeld, M. 1991. Commodity Trade and International Risk Sharing: How Much Do Financial Markets Matter?, Journal of Monetary Economics, 28, 3-24.

9. Dillén, Hans, and Edlund, M. 1997. EMU expectations and interest rates, Bank of Sweden, Quarterly Review 2/97.

10. Engle, R. 1982. A Autoregressive conditional heteroskedasticity with estimates of the variance of U.K inflation@, Econometrica, 50, 987-1008.

11. Favero, C. A., Giavazzi, F., Iacone, F., and Tabellini, G. 2000. Extracting Information From Asset Prices: The Methodology of EMU Calculators, European Economic Review, 44, 1607-1632.

12. Frankel, J. 1982. In search of the exchange rate risk premium: a six currency test assuming mean-variance optimization, Journal of International Money and Finance, 1, 255-274.

13. Hansen, L. P. and Hodrick, R. J. 1983. Risk averse speculation in the forward foreign exchange market: an econometric analysis of linear models @, in Frankel, J.A., Exchange Rates and International Macroeconomics, University of Chicago Press. Chicago.

14. Hodrick, R. J. 1989. Risk, uncertainty, and exchange rates, Journal of Monetary Economics, 23, 433-459.

15. Hodrick, R. J. 1987. The empirical Evidence on the Efficiency of Forward and Futures Foreign Exchange Markets, Harwook Academic Publishers, Chur.

16. Hu, X., 1997. Macroeconomic uncertainty and risk premium in the foreign exchange market, Journal of International Money and Finance, 16, 699-718.

17. J. P. Morgan. 1997. The EMU calculator handbook, Technical note, London.

18. Kaminsky, G. L. and Peruga, R. 1990. Risk premium and the foreign exchange market, Journal of International Economics, 28, 47-70.

19. Kaminsky, G. L and Peruga, R. 1991. Credibility crises: The dollar in the early 1980s, Journal of International Money and Finance, 10, 170-192.

20. Krasker, W. 1980. The peso problem in testing the efficiency of forward exchange markets, Journal of Monetary Ecomomics, 6, 269-276.

21. Lewis, K. 1988. The persistence of the peso problem when policy is noisy, Journal of International Money and Finance, 7, 1-11.

22. Lucas, R. E. Jr. 1982. Interest rates and currency prices in a two country world, Journal of Monetary Economics, 10, 335-359.

23. Peruga, R. and Fernández, J. L. 1997. Un contraste ADF secuencial para la detección de cambios en la tendencia estocástica, mimeo, Universidad Complutense de Madrid (ICAE) and Universidad Europea de Madrid.

24. Soderlind, P. Svensson, L. E. O. 1997. New Techniques to extract market expectations form financial instruments. Discussion paper, ${ }^{\circ} 1556$, CEPR, London, UK.

25. Zivot, E. and Andrews, D. 1992. Further evidence on the great Crash, the Oil Price Shock, and the unit root hypothesis, Journal of Business \& Economic Statistics, 10, 251-270. 


\section{APPENDIX}

Table 1:

Maximum Likelihood Estimation. GARCH Models

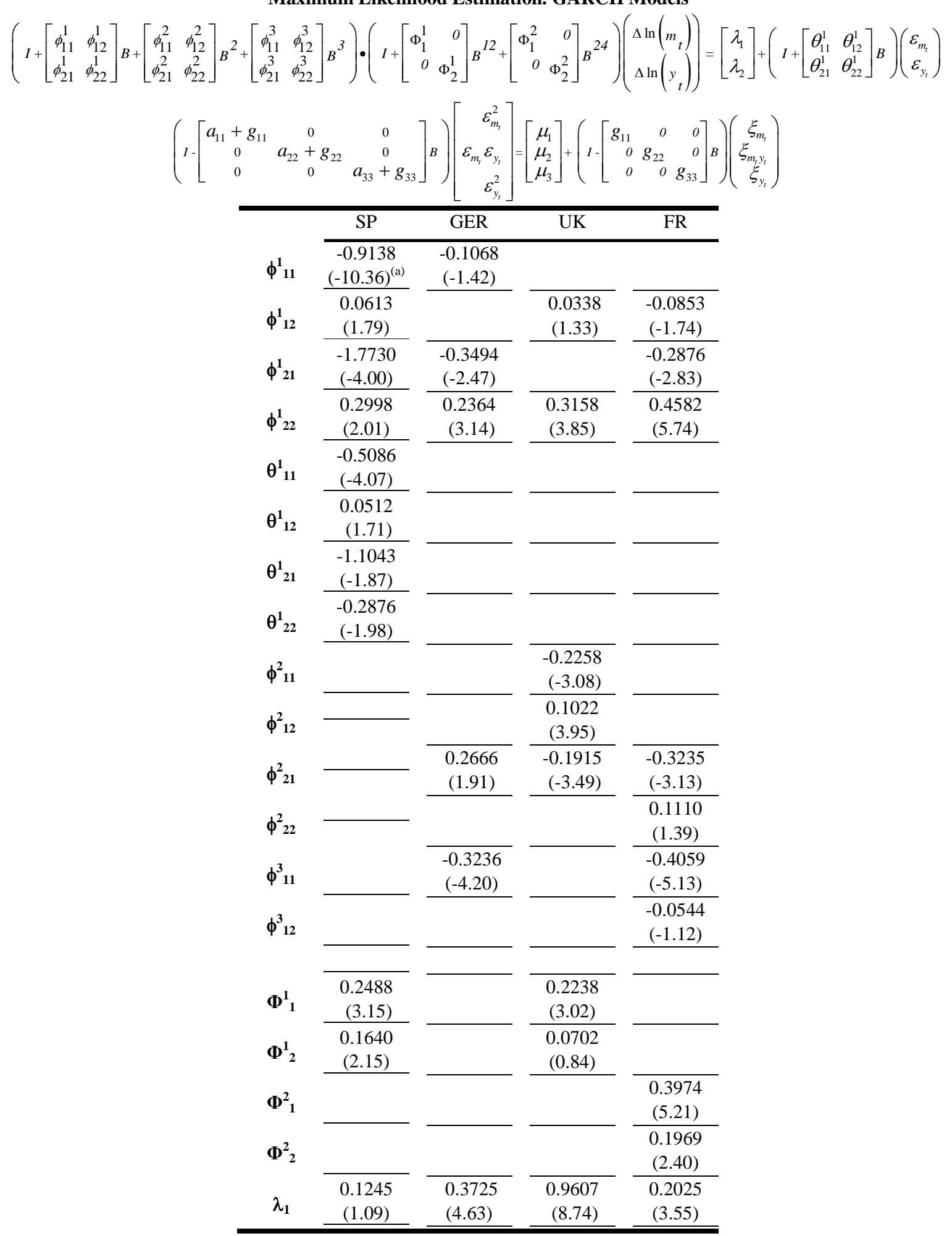




\begin{tabular}{|c|c|c|c|c|}
\hline$\lambda_{2}$ & $\begin{array}{l}-2.0981 \\
(-3.57)\end{array}$ & & & \\
\hline$\mu_{1}$ & $\begin{array}{r}0.0756 \\
(8.57) \\
\end{array}$ & $\begin{array}{c}0.2313 \\
(8.58)\end{array}$ & $\begin{array}{l}0.0710 \\
(5.79)\end{array}$ & $\begin{array}{l}0.3385 \\
(4.99)\end{array}$ \\
\hline$\mu_{2}$ & $\begin{array}{c}0.0595 \\
(2.79) \\
\end{array}$ & & & \\
\hline$\mu_{3}$ & $\begin{array}{l}1.5527 \\
(8.57) \\
\end{array}$ & $\begin{array}{l}1.1964 \\
(8.58)\end{array}$ & $\begin{array}{c}0.9311 \\
(2.00)\end{array}$ & $\begin{array}{l}0.7385 \\
(8.56)\end{array}$ \\
\hline$a_{11}+g_{11}$ & & & $\begin{array}{c}-0.2790 \\
(-2.05) \\
\end{array}$ & $\begin{array}{l}-0.9096 \\
(-7.48) \\
\end{array}$ \\
\hline$a_{22}+g_{22}$ & $\begin{array}{r}-0.6156 \\
(-1.85) \\
\end{array}$ & $\begin{array}{r}-0.8246 \\
(-8.95)\end{array}$ & & $\begin{array}{l}-0.8992 \\
(-3.38)\end{array}$ \\
\hline$a_{33}+g_{33}$ & & & $\begin{array}{l}-0.9941 \\
(-52.37) \\
\end{array}$ & \\
\hline $\mathrm{g}_{11}$ & & & & $\begin{array}{c}-0.8381 \\
(-5.13)\end{array}$ \\
\hline $\mathbf{g}_{22}$ & $\begin{array}{c}-0.7092 \\
(-2.37) \\
\end{array}$ & $\begin{array}{l}-0.9273 \\
(-15.44)\end{array}$ & & $\begin{array}{c}-0.8741 \\
(-2.95)\end{array}$ \\
\hline $\mathbf{g}_{33}$ & & & $\begin{array}{l}-0.9253 \\
(-15.47) \\
\end{array}$ & \\
\hline
\end{tabular}

Table 2:

Least Squares Estimation Of The Risk Premium Associated To Macroeconomic Uncertainty. Full Sample: 1986:02-1998:04 ${ }^{(\mathrm{A})(\mathrm{B})}$

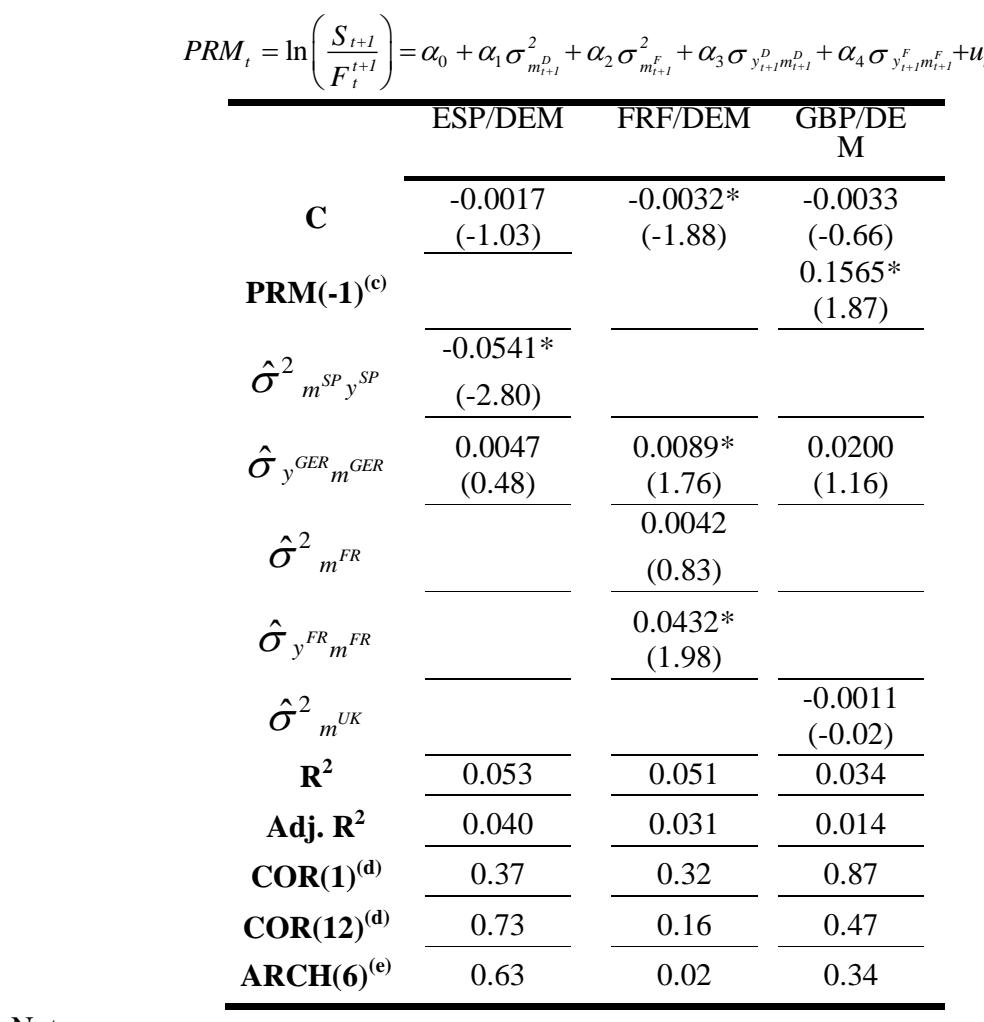



(a) t-statistics in parentheses
(b) An asterisk denotes a coefficient significant at the $10 \%$ level
(c) PRM(-1) denotes the lagged risk premium
(d) $\quad P$-value of Breusch-Godfrey test statistic for residual serial correlation up to lag order $p$.
(e) Autoregressive conditional heteroskedasticity test. $\mathrm{ARCH}(6)$ is the p-value of LM test statistic.

Table 3: ${ }^{(a)}$

Least Squares Estimation Of The Risk Premium Associated To Policy Uncertainty. Sample: 1994:01-1998:04

\begin{tabular}{|c|c|c|c|}
\hline \multirow[t]{2}{*}{$P R M_{t}=\ln$} & \multicolumn{3}{|c|}{$=\gamma_{0}+\gamma_{1} I R_{-} S P R_{t}+\gamma_{2} I R_{-} S P R 2_{t}+u_{t}$} \\
\hline & ESP/DEM & FRF/DEM & GBP/DEM \\
\hline C & $\begin{array}{c}-0.0061 \\
(-1.83)\end{array}$ & $\begin{array}{c}-0.0016 \\
(-1.46)\end{array}$ & $\begin{array}{l}0.0242 \\
(1.25)\end{array}$ \\
\hline$I R \_S P R$ & $\begin{array}{c}0.4651 \\
(1.81)\end{array}$ & $\begin{array}{l}0.8758 \\
(1.87)\end{array}$ & $\begin{array}{c}-1.5313 \\
(-0.9)\end{array}$ \\
\hline$I R \_S P R 2$ & $\begin{array}{l}-10.017 \\
(-2.33)\end{array}$ & $\begin{array}{l}-101.11 \\
(-2.84)\end{array}$ & $\begin{array}{l}6.3577 \\
(0.13)\end{array}$ \\
\hline$\underset{\text { Uncertainty }^{(\mathbf{b})}}{\text { Policy }}$ & 0.022 & 0.002 & 0.022 \\
\hline $\mathbf{R}^{2}$ & 0.144 & 0.223 & 0.144 \\
\hline Adj. $\mathbf{R}^{2}$ & 0.109 & 0.192 & 0.109 \\
\hline $\operatorname{COR}(1)^{(\mathrm{c})}$ & 0.87 & 0.24 & 0.53 \\
\hline $\operatorname{COR}(12)$ & 0.90 & 0.59 & 0.30 \\
\hline $\operatorname{ARCH}(6)^{(\mathbf{a})}$ & 0.16 & 0.64 & 0.57 \\
\hline
\end{tabular}

Notes:

(a) $\quad$-statistics in parentheses

(b) P-value of F-statistic for the null hypothesis: $\mathrm{H}_{0}: \gamma_{1}=\gamma_{2}=0$.

(c) $\quad P$-value of Breusch-Godfrey test statistic for residual serial correlation up to lag order $p$

(d) Autoregressive conditional heteroskedasticity test. $A R C H(6)$ is the p-value of LM test statistic. 
Table 4:

Least Squares Estimation Of The Risk Premium Equation ${ }^{(a)}$ Sample: 1994:01-1998:04

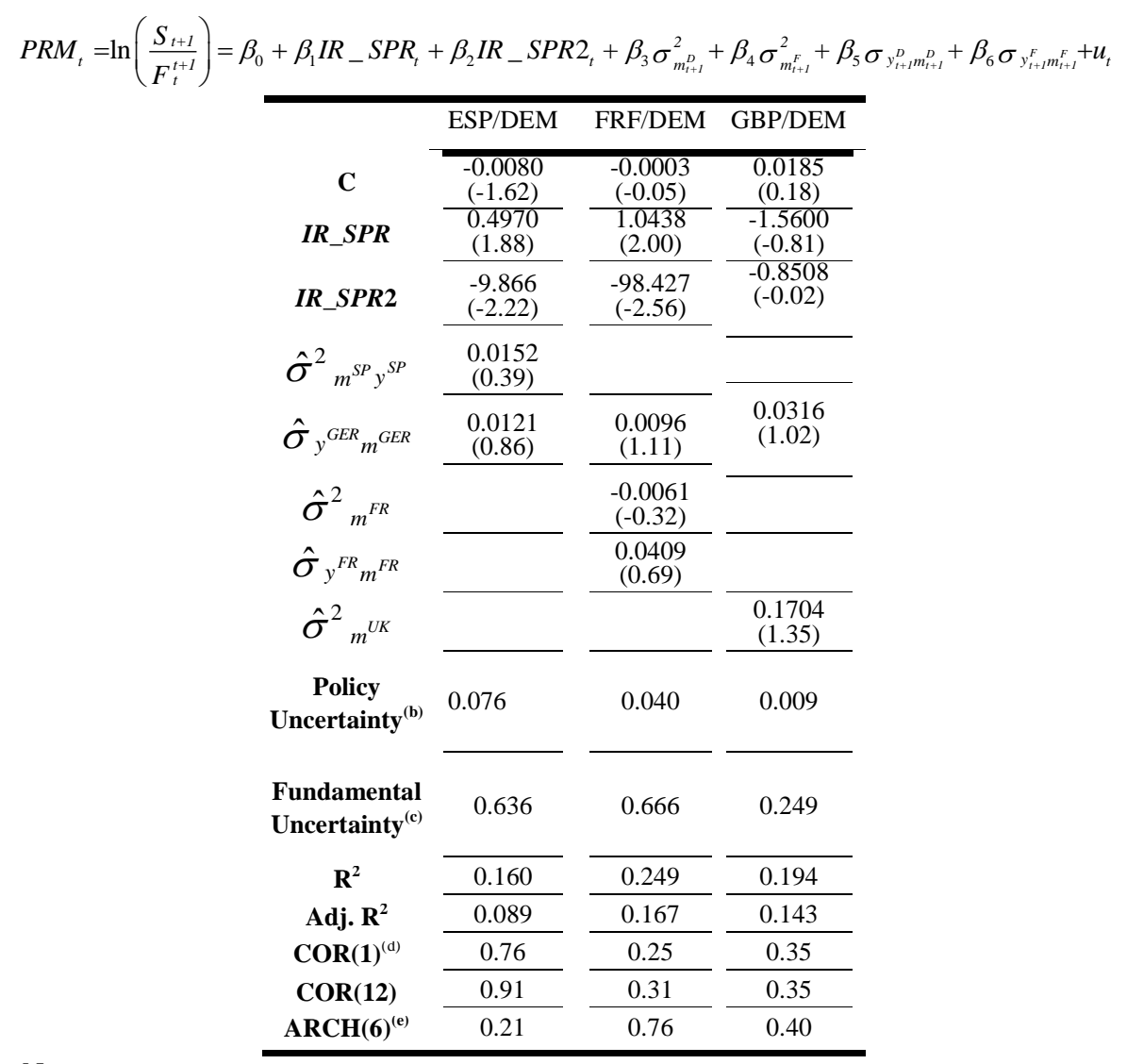

Notes:

(a) t-statistics in parentheses.

(b) P-value of F-statistic for the null hypothesis: $\mathrm{H}_{0}: \beta_{1}=\beta_{2}=0$.

(c) P-value of F-statistic for the null hypothesis: $\mathrm{H}_{0}: \beta_{3}=\beta_{4}=\beta_{5}=\beta_{6}=0$

(d) $\quad P$-value of Breusch-Godfrey test statistic for residual serial correlation up to lag order $p$

(e) Autoregressive conditional heteroskedasticity test. $\mathrm{ARCH}(6)$ is the p-value of LM test statistic. 
Figure 1:

Effects On The Risk Premium And The Variance Of Fiscal Policy

Of A Change In $P_{t}$

ᄂ

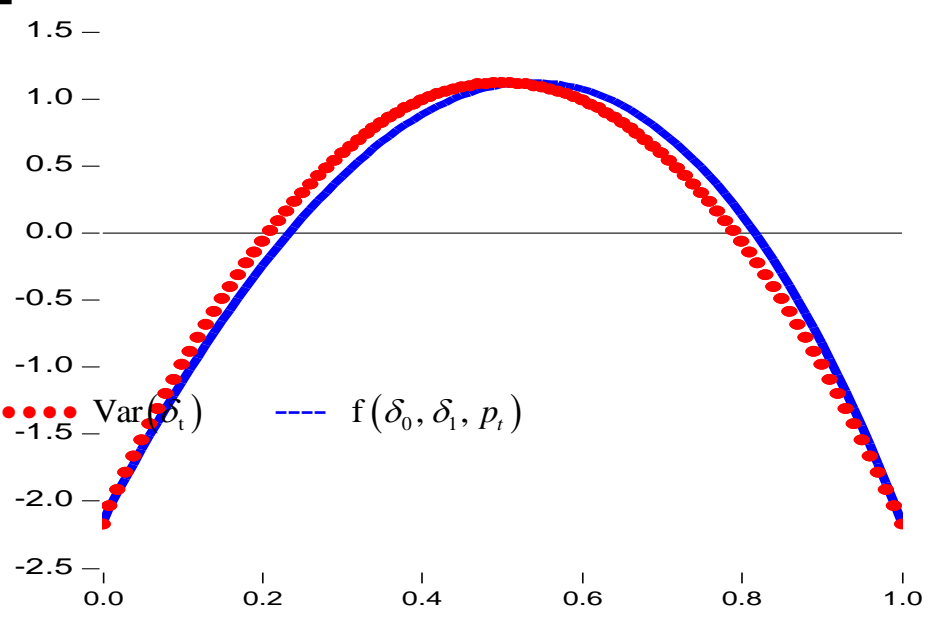

Notes:

(a) Both variables are standardized

(b) $\quad p_{t}$ : probability that there might be a change in fiscal policy, is shown in the horizontal axis

(c) $\mathrm{f}\left(\delta_{0}, \delta_{1}, \mathrm{p}_{\mathrm{t}}\right)$ is the non-linear function of $p_{t}$ measuring the effect on the risk premium of changes in $p_{t}$, as in (18).

(d) $\operatorname{Var}\left(\delta_{\mathrm{t}}\right)=\mathrm{p}_{\mathrm{t}}\left(1-\mathrm{p}_{\mathrm{t}}\right)\left(\delta_{1}-\delta_{0}\right)^{2}$ is the non-linear function of $p_{t}$ providing the variance of fiscal policy

Figure 2:

Interest Rate Swap Spreads (IR_SPR) And Observed Risk Premium (PRM)

Sample: 1994:01-1998:04
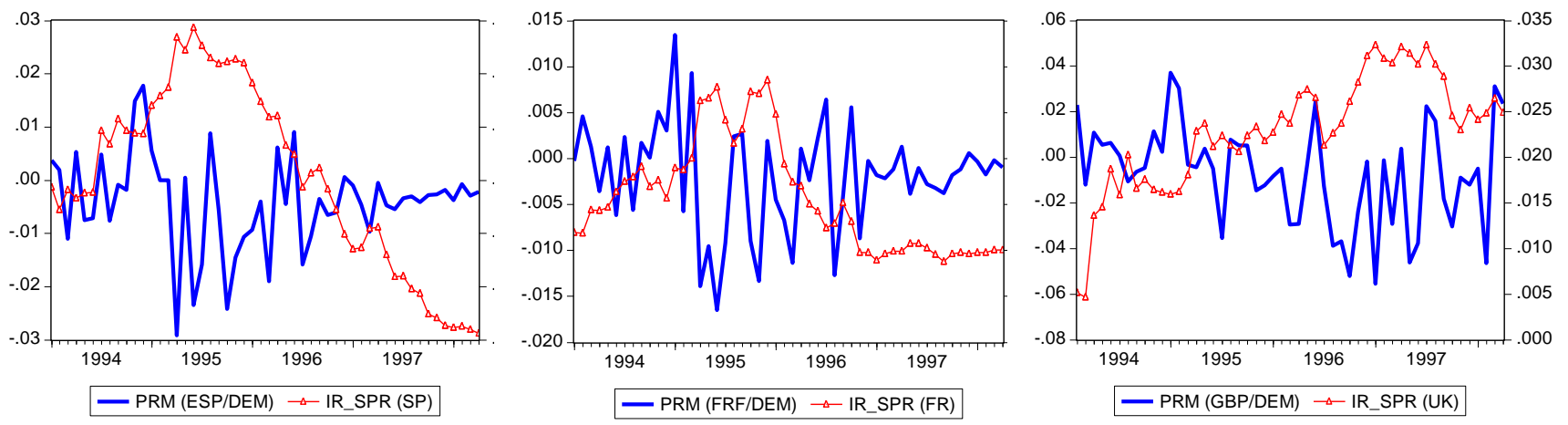
Figure 3:

Observed Risk Premium, Fitted Risk Premium, Macroeconomic Uncertainty And Policy Uncertainty ${ }^{(\mathrm{a})(\mathrm{b})(\mathrm{c})}$

Sample: 1994:01-1998:04

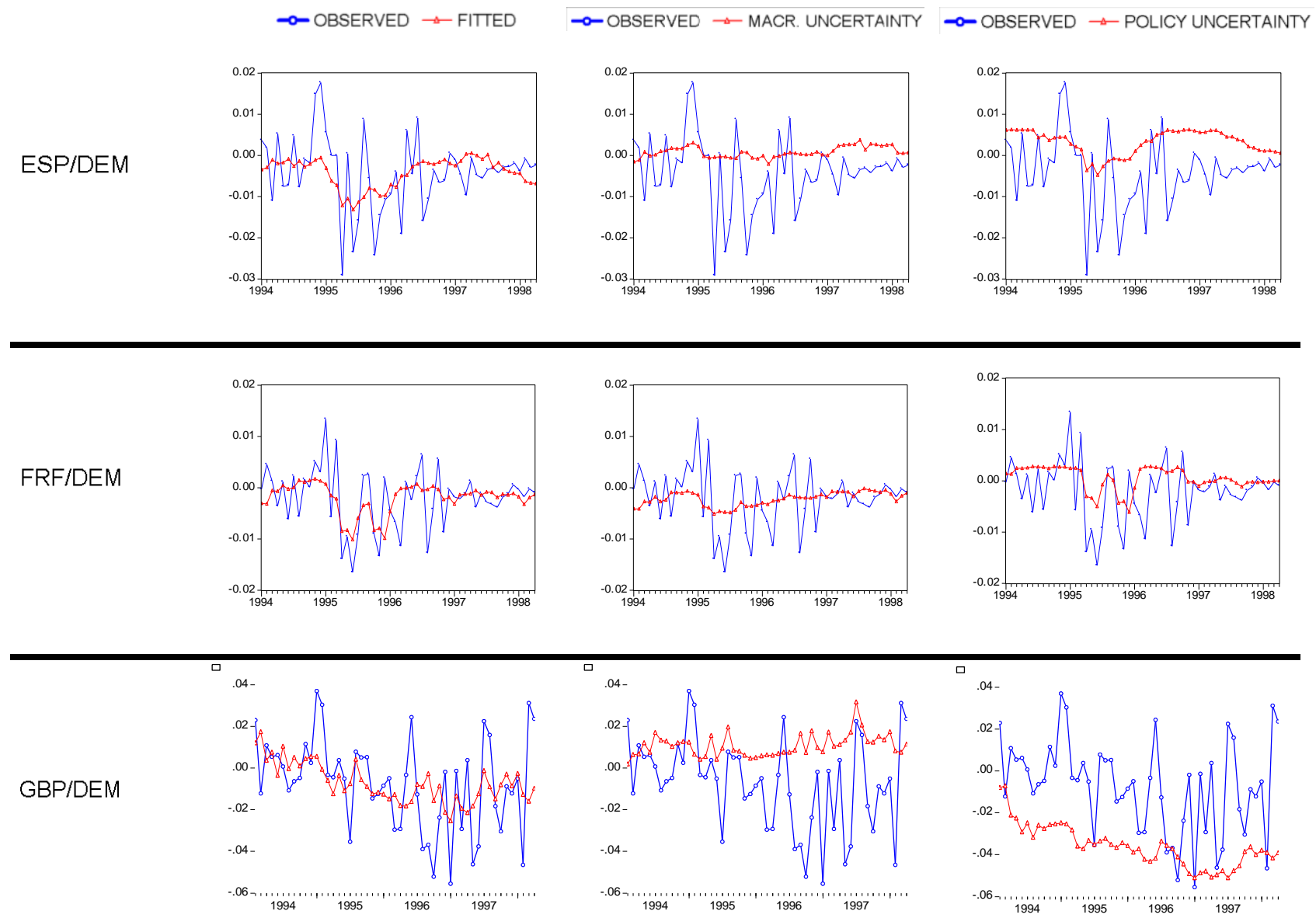

Notes:

(a) Left column: Observed exchange risk premium versus the fitted value from the model in Table 4

(b) Middle column: Observed exchange risk premium versus macroeconomic uncertainty contribution

(c) Right column: Observed exchange risk premium versus fiscal policy uncertainty contribution

Figure 4:

Probability Indicator For Spain, France And United Kingdom Sample: 1994:01-1998:04
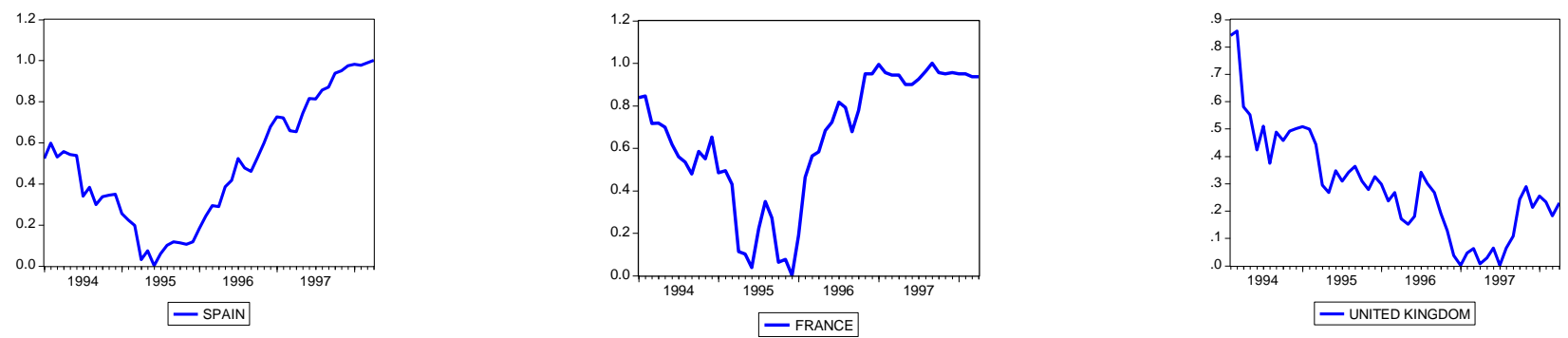
Figure 5:

Scatter Diagrams: Fitted Risk Premium (Horizontal Axis) Versus Observed Risk Premium, Policy And Macroeconomic Uncertainty Contribution ${ }^{(\mathbf{a})(\mathbf{b})(\mathbf{c})}$.

Sample: 1994:01-1998:04

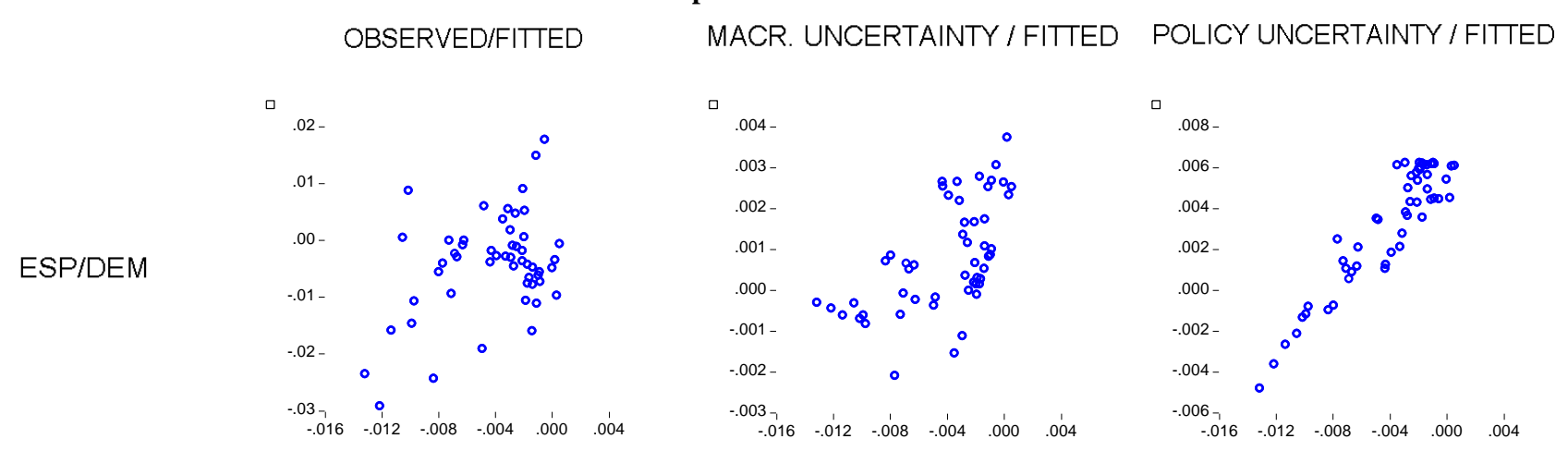

Correlation $^{(d)}$

0.40

0.58

0.93

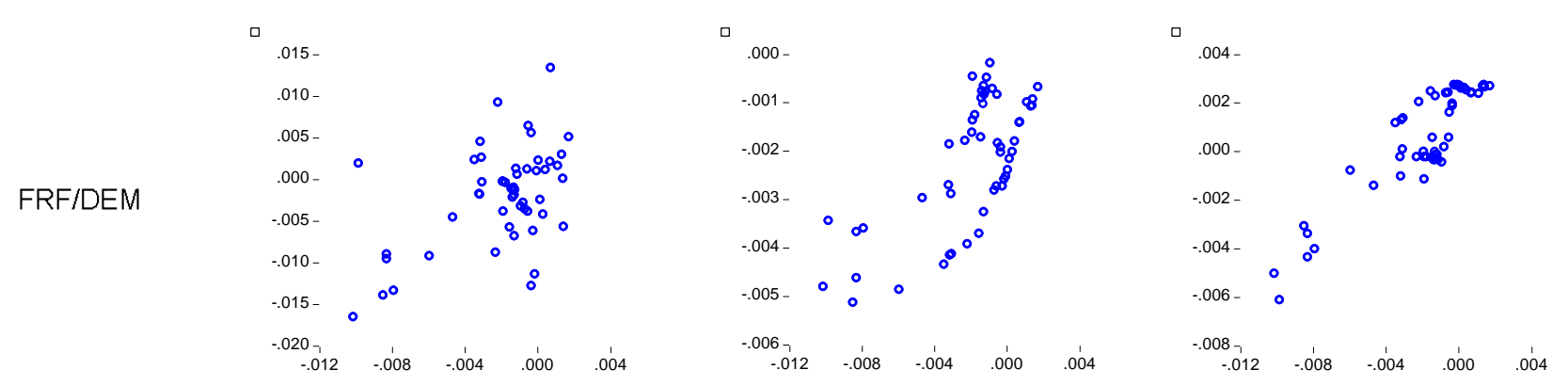

Correlation $^{(d)}$

0.32

0.70

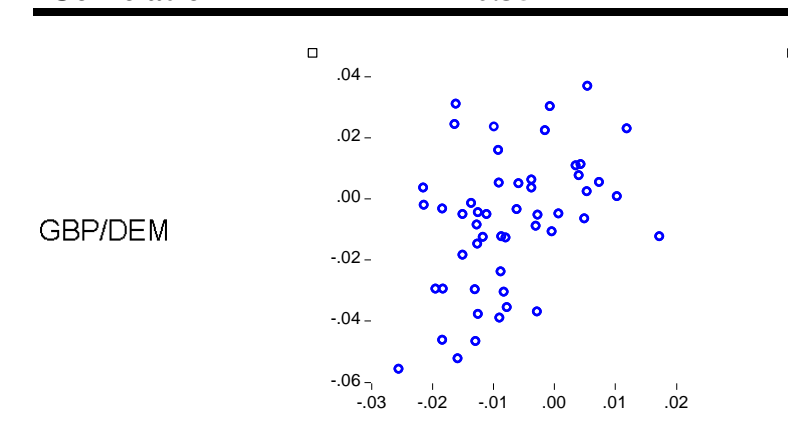

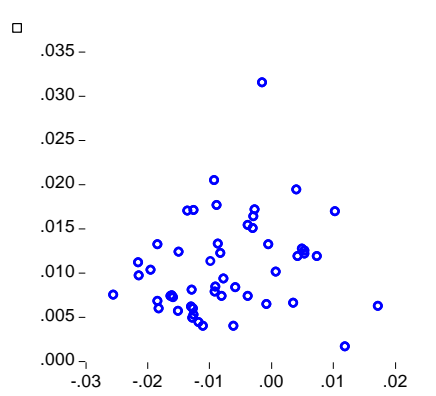

․ .00

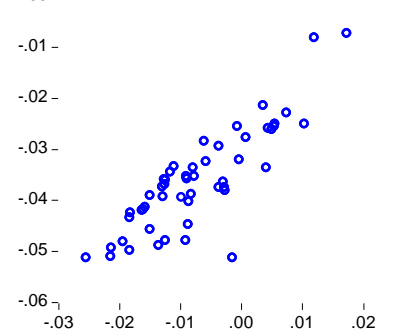

Correlation $^{(d)}$

0.41

0.19

0.85

Notes:

(a) Left column: observed risk premium versus the fitted risk premium from the model in Table 4

(b) Middle column: Macroeconomic uncertainty contribution versus the fitted risk premium

(c) Right column: Policy uncertainty contribution versus the fitted risk premium

(d) Correlation between variables in scatter diagrams 